\title{
A relação entre lei e poder em Hannah Arendt
}

\author{
Maria Aparecida Azevedo de Abreu
}

\section{Resumo}

O objetivo do texto é relacionar o conceito de lei e o de poder na obra de Hannah Arendt. Na obra da autora, o poder é algo que emerge da ação e está fortemente relacionado com a liberdade, sendo, nesta medida, uma noção bastante fecunda e eminentemente localizada no espaço político. Em contrapartida a lei, tal como vista por Arendt, tem sua elaboração situada fora do espaço político, pertencendo a este espaço somente o consentimento ou dissenso à lei. Com isto, na perspectiva da autora, enquanto a lei é resultado de um processo pré-político, o poder é um produto eminentemente político. Trata-se, portanto, de uma relação "pouco tensa".

O objetivo deste trabalho é verificar em que medida se estabelece a relação entre os conceitos de lei e poder na obra de Hannah Arendt. Para traçar tal relação, em primeiro lugar, será exposta a noção de espaço político que permeia toda a obra da autora, para que os conceitos de lei e poder possam ser situados em relação a esse espaço. Feito isto, será traçada a relação entre lei e poder.

Pretende-se, com isto, verificar a densidade da relação entre um conceito que é extremamente forte na obra de Arendt, que é o conceito de poder, e outro que parece ser apenas um sustentáculo, ainda que fundamental, do espaço político, que é o conceito de lei. 


\section{O espaço político arendtiano}

O espaço político definido por Arendt é aquele em que são realizados a ação e o discurso humanos, sendo nesta medida o espaço para a revelação e a comunicação dos agentes. A primeira acontece através da exposição da singularidade de cada agente, quando este deixa no espaço político seus feitos e discursos. A segunda acontece através do agir conjunto e da troca de opiniões objetivando a persuasão.

Seja como lugar para a revelação, ou como lugar para a comunicação, ${ }^{1}$ o espaço político é eminentemente lugar de aparências: os agentes não aparecem para a política com sua fragilidade individual e com todas as preocupações de sua vida privada, mas sim representando $e$ levando a público a sua capacidade de agir e de persuadir. Para levar adiante esta capacidade, a pessoa tem de libertar-se de suas necessidades e de tudo aquilo que a orienta no processo vital, que objetiva a sobrevivência.

No pensamento arendtiano, portanto, é na esfera pública que se localiza o espaço político, não devendo serem levadas a ele questões da esfera privada. E porque está situado na esfera pública e é espaço de representações, o espaço político é considerado pela autora como um artifício humano em que os homens podem ser considerados iguais $e$, ao mesmo tempo, exporem-se como seres plurais. Porque os homens são iguais no espaço político é que pode haver comunicação $e$ persuasão, e porque os homens são plurais é que faz sentido a revelação de cada um no espaço público.

Sendo o espaço da ação e do discurso humanos, o espaço político é a esfera da liberdade e da imprevisibilidade humanas: com a ação, algo novo se inicia, sem que haja fins previsíveis, podendo o ser humano ser livre, agindo em conjunto com seus iguais. Por causa da imprevisibilidade que caracteriza a ação, o espaço político é extremamente frágil, tornando necessário algo que assegure a sua existência.

1 Entre os comentadores da obra da autora, é colocado em questão várias vezes se Arendt teria enfatizado a idéia de uma ação que revelaria os agentes, chamada de heróica, ou se teria enfatizado o aspecto comunicacional ou participativo da ação (D'Entrèves). Para os fins deste texto, entendo que tal discussão é irrelevante e por isso não vou abordá-la aqui. 
Com todas estas características atribuídas ao espaço político artificialidade, fragilidade e contingencialidade - Arendt admite que ele se configura raramente, tendo ocorrido poucas vezes na história. ${ }^{2} \mathrm{~A}$ autora utiliza a polis grega como metáfora desse espaço e identifica quais elementos da polis se repetem toda vez que o espaço político acontece. Dentre esses elementos, os mais marcantes são a geração de poder e a instauração da liberdade. ${ }^{3}$ Poder e liberdade, portanto, não fazem parte dos acontecimentos ordinários, mas são eventos extraordinários, cuja ocorrência é imprevisível.

Na medida em que se revela a raridade e a fragilidade do espaço político e além disso, sua imprevisibilidade, é impossível garantir que ele aconteça, mas ao mesmo tempo torna-se fundamental identificar o que pode assegurar, ao menos, a possibilidade de que ele aconteça. Um dos instrumentos para que essa garantia seja obtida, e talvez o mais importante deles, são as leis, tema que passa a ser abordado agora.

\section{A concepção arendtiana de lei entre o político e o pré- político}

Diante da fragilidade do espaço político gerada pela imprevisibilidade da ação humana, Arendt aponta a necessidade de que haja limites para tal imprevisibilidade, que são traçados através de instituições. ${ }^{4}$ Dentre essas instituições, as leis emergem como importantes elementos constituintes da estrutura do espaço político. A partir de leis

Arendt, H. 1981, p. 211.

Arendt, H. 1988.

4 Além das instituições Arendt aponta outros "remédios" para a imprevisibilidade da ação e a insegurança dela decorrente. Em relação à imprevisibilidade da ação, decorrente da pluralidade humana e da capacidade de gerar novos começos, a autora sugere que a capacidade de fazer promessas possa dar limites a essa imprevisibilidade. Quanto à irreversibilidade da ação, decorrente da impossibilidade de refazê-la, ou "retirá-la" do mundo, Arendt aponta que o perdão possa apagar seus efeitos. Por fim, para assegurar alguma permanência da ação no mundo, a autora aponta a figura do storyteller e da formação de memória acerca dos eventos políticos. Todas estas soluções apontadas pela autora merecem discussão apropriada, que não será realizada aqui. 
devidamente observadas, tem-se, para Arendt, a possibilidade de garantia da existência do espaço político em potencialidade, através da limitação da ação humana.

Além dessa garantia à existência do espaço político, o conjunto das leis, na medida em que confere direitos aos indivíduos, atribui a estes uma artificialidade que lhes dá possibilidade efetiva de agir representando. A representação é possível porque os indivíduos revestem-se de uma persona, que os coloca na esfera pública como iguais, e como seres dotados de direitos e não com a fragilidade da vida privada. Esta persona é que faz o indivíduo integrar o espaço político como cidadão e não apenas como indivíduo.

A lei assume, assim, um papel crucial como elemento de viabilização da ação humana entre iguais e do próprio espaço político. No entanto, apesar desse papel, Arendt alerta para a necessidade de que a lei não ultrapasse a função limitadora da ação e do espaço político e não passe a prescrever a ação humana. Isto destituiria a ação de sua característica essencial, que é a imprevisibilidade e a capacidade de gerar algo inteiramente novo.

Esse papel que Arendt dá à lei de limitar - e apenas limitar - a ação humana, conforme pode ser verificado na seguinte passagem: "A legalidade impõe limites aos atos, mas não os inspira; a grandeza, mas também a perplexidade, das leis nas sociedades livres está em que apenas dizem o que não se deve fazer, mas nunca o que se deve fazer", ${ }^{5}$ acaba por restringir as possibilidades de conteúdo de um texto legal. Talvez por isto Arendt não tenha se preocupado, ao longo de sua obra, com os processos de elaboração de textos legislativos. Assim, apesar de dar à lei um papel fundamental, a autora não dedica análise ao processo que determina o conteúdo das leis. Com isto, embora Arendt considere a lei como algo obtido artificialmente e de conteúdo relativo, não sendo, portanto, algo natural ou absoluto, o que a coloca inserida em uma tradição política republicana, ${ }^{6}$ sua

Arendt, H. 1990, p. 519.

6 Esta "filiação" de Arendt a uma tradição política romana é apontada por André Duarte da seguinte forma: "Arendt assume-se como herdeira direta dessa linhagem 'republicana', a qual pertencem Montesquieu e Maquiavel, quando afirma que as leis não carecem de uma 'fonte transcendente de autoridade, ou seja, uma origem que deva situar-se para além do poder humano', independentemente do 
concepção parece estar mais próxima da grega, e principalmente daquela traçada por Aristóteles. ${ }^{7}$

Essa concepção que prevalece na obra de Arendt acaba colocando a lei como algo que pode ser obtido de uma forma não necessariamente política. Aliás, pode-se dizer que sua função limitadora somente ocorre se assim for obtida. ${ }^{8}$ Nesta perspectiva, o texto legal pode ser obtido através da atividade de fabricação - da forma mais elevada, é verdade - o que coloca sua elaboração fora do espaço político.

O texto legal, elaborado de uma forma não política, necessita, segundo Arendt, do consentimento daqueles que vão observá-lo. ${ }^{9}$ Este consentimento é necessário para que o espaço político seja efetivamente preservado, pois sem ele a lei, ao invés de instrumento garantidor, passa a ser ameaçador da existência do espaço político. Embora haja tal preocupação da autora de que exista um consentimento para

consentimento e dos acordos mútuos". (Duarte, p. 249). No entanto, a filiação de Arendt a uma concepção romana de lei parece terminar aí. Segundo afirmado pela própria autora e citado por Duarte, os romanos compreendem a lei como "algo que forma novas relações entre os homens" (Duarte, p. 249, grifo meu). Ora, conforme apontado em citação anterior, segundo a autora, a lei não forma, apenas diz o que não se deve fazer, ela limita e não inspira. A lei romana, ao contrário, é essencialmente política desde o seu processo de elaboração e não somente quando é consentida pelos agentes políticos. Por isto é que Maquiavel, nos seus discursos sobre a obra deTito Lívio, afirma que a liberdade romana era gerada pelo conflito entre senado e povo, o que ocasionava a elaboração de leis que intermediassem esse conflito (Maquiavel, p. 31-2). No mundo romano enxergado por Maquiavel através de Tito Lívio há, portanto, uma estreita relação conflito-lei-liberdade, que não pode ser admitida na obra de Hannah Arendt. Para a autora, a lei garante a liberdade, mas não a produz.

7 Para verificar a exclusão aristotélica da atividade legisladora do âmbito político, ver Aristóteles, p. 219 e p. 240 e Wolff, p. 140.

8 Neste sentido, ver a passagem: "As cercas que inscrevem a propriedade privada e protegem os limites de cada domićlio, as fronteiras territoriais que protegem $e$ tornas possível a identidade física de um povo, e as leis que protegem e tornam possível sua existência política, têm enorme importância para a estabilidade dos negócios humanos precisamente porque nenhum princípio limitador e protetor resulta das atividades que transcorrem na própria esfera dos negócios humanos" (Arendt, 1981, p. 204).

9 A respeito desta necessidade de um consensus juris, a análise de Hannah Arendt volta-se principalmente para a sua ausência no governo totalitário (Arendt, 1991, p. 512 e ss.) 
que uma lei seja observada, isto não confere ao conteúdo da lei um caráter político, pois sua elaboração permanece fora do espaço político. O que pertence a este espaço é a decisão acerca da obediência ou não da lei, mas não sua formulação.

Com tudo isto, pode-se dizer que a lei, na concepção arendtiana, somente se encontra no espaço político ao ser consentida. A lei integra a estrutura do espaço político mas não emerge dele.

\section{Poder e liberdade: produto e sentido da política}

Na obra de Hannah Arendt a definição de poder é realizada através de suas formas de manifestação. Neste sentido, pode-se dizer que a definição mais abrangente é a de que "o poder é originado sempre que um grupo de pessoas se reúne e age de comum acordo". ${ }^{10}$ Com esta relaçào entre poder e ação, a autora situa o poder nos limites estritos do espaço político, já descritos anteriormente.

Ora, sendo o espaço político o lugar em que os homens realizam o exercício de ser livre, também é estreita a relação entre poder e liberdade. Poderia ser arriscada até mesmo uma outra definição: poder é aquilo que emerge da ação livre de pessoas em conjunto. E note-se que aqui nem é necessário situar tal ação no espaço político, pois se a ação é livre ela só pode acontecer em tal espaço. ${ }^{11}$

Com esta relação entre poder, liberdade e espaço político, percebe-se que o poder é algo que raramente emerge e, quando isto acontece, pode-se dizer também que não se trata de um fenômeno permanente, que se instala no espaço político. Ao contrário, "o poder precisa

10 Arendt, H. 1985, p. 28.

11 Talvez haja redundância em dizer "ação livre" e "seres humanos em conjunto", pois para Arendt somente pode haver ação livre realizada por um conjunto de pessoas. Neste sentido, vale trazer aqui a passagem: "O poder corresponde à habilidade humana de não apenas agir, mas de agir em uníssono, em comum acordo. O poder jamais é propriedade de um indivíduo, pertence ele a um grupo e existe apenas enquanto o grupo se mantiver unido. Quando dizemos que alguém está "no poder" estamos nos referindo ao fato de encontrar-se esta pessoa investida de poder, por um certo número de pessoas, para atuar em seu nome" (Arendt, 1985, p. 24). De qualquer forma, isto não torna a definição incorreta. 
ser constantemente exercitado e recriado através da ação". ${ }^{12} \mathrm{E}$ o agir conjunto e reiterado gera mais e mais poder legítimo. A legitimidade do poder é dada pelo seu próprio momento inicial, em que os cidadãos se reúnem. E aqui vale destacar a distinção que Arendt faz entre legitimidade e justificação do poder. Para ela, a legitimidade do poder "deriva da reunião inicial e não de qualquer ação que possa se seguir. A legitimidade, quando desafiada, baseia-se em um apelo ao passado, enquanto a justificativa diz respeito a um fim que se encontra no futuro". ${ }^{13}$

E nem poderia ser diferente: se o poder deriva da ação e esta é algo essencialmente imprevisível, nenhuma finalidade poderia ser considerada como medida para avaliar o poder originado, pois significaria impor fins à ação, o que a descaracterizaria.

Se for associada a estas considerações uma outra observação feita pela autora de que "todas as instituições políticas são materializações de poder", ${ }^{14}$ pode-se considerar que as instituições políticas são legítimas quando são resultado de um comum acordo de cidadãos. A finalidade dessas instituições políticas não importa, assim, para a averiguação de sua legitimidade. Com esta retirada da finalidade como medida para a ação política, pode-se dizer que, para Arendt, a ação é realizada apenas para que seja exercitada a liberdade, ou seja, que a liberdade é o "sentido da política" e, portanto, do próprio poder. ${ }^{15}$

\section{Poder e lei: uma relação pouco tensa}

A associação entre a legitimidade do poder $e$ a das instituições torna-se um pouco problemática quando tentamos aplicá-la às leis. Como já dito, as leis dependem do consentimento dos cidadãos para que sejam observadas. E, como já dito, sua formulação não é uma questão relevante para Arendt. Então pode-se concluir que o texto le-

12 D'Entrèves, p. 79.

13 Arendt, H. 1985, p. 28.

14 Arendt, H. Crises of the Republic.

$15 \mathrm{O}$ conceito arendtiano de poder envolve uma série de outros aspectos que não serão abordados neste texto. Foram tomados apenas elementos necessários para confrontá-lo com a noção de lei presente na obra da autora. 
gal quando formulado ainda não pode ser considerado como resultado de uma ação política e nem mesmo pode ser considerado como legítimo. Sua legitimidade se inicia quando há o consentimento de cidadãos para a sua obediência e, portanto, sua existência política também ali se inicia.

A relação entre lei e poder, portanto, se resume ao momento da obediência da lei, não existindo em nenhum momento anterior. Dentro deste esquema, a lei não emerge da mesma ação da qual o poder emerge. Ela pode cristalizar a manifestações do poder, mas não é ela própria uma manifestação sua.

Em outras palavras, o texto legal depende da formação de um poder político que, consentindo acerca desse texto legal, confere a este legitimidade e dá início à sua dimensão política, mas em nenhum momento Arendt fala de qualquer poder como necessário para a elaboração de leis.

Talvez isto fique mais explícito com a passagem em que Arendt afirma que "A lei pode realmente estabilizar e legalizar mudanças uma vez que elas tenham ocorrido, mas a mudança em si mesma é sempre resultado de uma ação extra-legal". ${ }^{16}$ Com esta observação, Arendt pretende dizer que primeiro ocorre a mudança no espaço político, mudança esta que pode ser obtida até mesmo através da desobediência à lei, para que depois a lei reconheça esta mudança. Tudo estaria perfeito se junto a esta idéia não estivesse uma outra de que o processo legislativo, em si mesmo, não pode ser um instrumento de mudanças. Isto porque, no esquema arendtiano, a lei não expressa conflitos, mas sim mudanças já ocorridas, apenas cristalizando-as. Desta forma, faz todo sentido que a lei possa ser obtida através de um processo não necessariamente político, e até mesmo de fabricação, pois o processo legislativo, neste ponto de vista, tem a função exclusiva de colocar como lei algo que já se consolidou no espaço político, dando-lhe apenas permanência e durabilidade. ${ }^{17}$ Além disso, o processo legislativo possui, em relação ao espaço político arendtiano, um fim muito específico. Ora, a única atividade humana que possui, no pensamento da autora, um fim específico, é a fabricação.

16 Arendt, H. Crises of the Republic, p. 80, tradução minha.

17 Arendt, H. 1981, p. 105. 
A conseqüencia mais imediata da colocação da lei fora do espaço político é que não podemos imaginar, no esquema arendtiano, grupos agindo concomitantemente, com conflito de propósitos, buscando implementar a sua proposta de lei a ser seguida por todos. Esta concepção faz com que, embora Hannah Arendt admita expressamente a mutabilidade das leis, a mudança legislativa seja algo que só ocorre depois de uma mudança política já consolidada.

E esta conseqüência assume maiores dimensões no interior da obra da própria autora se for considerada a importância que a autora dá aos direitos para a constituição de cidadãos. Diante dessa limitada relação entre lei e poder, pouco há a fazer no sentido de buscar ampliação de direitos através da interferência direta no processo de formulação daquilo que institui estes direitos, que é a lei.

No esquema arendtiano, portanto, com esta distância estabelecida entre lei e poder, o que vale dizer entre lei e ação política, até mesmo a dimensão de sua concepção de cidadania fica reduzida. Assim, diante da tentativa de evitar que a lei assuma conteúdos excessivamente prescritivos, o que pode gerar de uma certa forma o totalitarismo, a autora terminou reduzindo demais a dimensão de uma noção extramamente rica em sua obra, que é a de cidadania.

A lei, neste esquema, não possui nenhum potencial modificador do espaço político. Para tê-lo, teria de ser colocada desde a sua formulação em um espaço que, para Arendt tem características específicas, como já mostrado, e para realizar essa inserção, é necessário afrouxar essas características. Mas para isto talvez seja preciso sair do âmbito da obra de Hannah Arendt.

\section{Referências bibliográficas}

ARENDT, Hannah. A Condição humana. Rio de Janeiro: Forense-Universitária, 1981.

. Crises of the Republic. New York: Harcourt Brace \& Company, 1994.

. As origens do totalitarismo. São Paulo: Cia. das Letras, 1990.

. Da revolução. São Paulo: Ática, 1988.

. Da violência. Brasília: Editora Universidade de Brasília, 1985.

ARISTóteles. A Política. Brasília: Editora Universidade de Brasília, 1995. 
D'EnTRÈVEs, M. Passerin. The political philosophy of Hannah Arendt. London: Routledge, 1994.

DuARTE, André. O Pensamento à sombra da ruptura - política e filosofia em Hannah Arendt. São Paulo: Paz e Terra, 2000.

Maquiavel, N. Comentários sobre a primeira década de Tito Lívio. Brasília: Editora Universidade de Brasília, 1994.

Wolff, Francis. Aristóteles e a Política. São Paulo: Discurso Editorial, 1999. 